\title{
Research on Continuous Tax Inspection
}

\author{
Zhenxin $\mathrm{Qu}^{\mathrm{a}}$, Wannian $\mathrm{Yu}^{\mathrm{b}}$ \\ School of Information and Safety Engineering, ZhongNan University of Economics and Law, Wuhan \\ 430073, China. \\ a408063260@qq.com, biamyuwannian@163.com
}

\begin{abstract}
Modern information technologies were not taken full advantage of, and methods of tax inspection ware relatively backward. Continuous tax inspection mode is designed based on cloud-computing and artificial intelligence. With this mode, taxpayers were inspected continuously and real-timely by means of information technologies. Continuous tax inspection is due to improve efficiency and quality of inspection work, and provide inspection service to the public. Challenges were analyzed and corresponding strategy was discussed in this paper.
\end{abstract}

Keywords: Tax inspection; continuous; cloud-computing.

\section{Introduction}

Tax inspection is a part of taxation in China and also an important means of promoting tax administration by law. Thus it plays a significant role in avoiding tax evasion and tax fraud. With the development of information technology, new technologies are able to provide more efficient inspection means and inspection mode, which makes it possible to reduce tax cost by improving the quality of tax inspection, the taxation enforcement efficiency and administrative efficiency. At present, information technologies are not taken fully advantage into tax inspection in China. Although electronic audit is partly used in tax inspection, the range of work that the Golden Tax Project can manage is very limited. On the whole, tax inspection is reduced to a passive position for the reason that it mainly focus on identifying problems rather than avoiding problems for a long run. This paper puts forward a new inspection mode called Continuous Tax Inspection, which is supported by the study of information technology. With Continuous Tax Inspection applied to inspection work, this new mode can help to avoid the loss of tax and crack down on tax evasion. What's more, it also helps to assist tax inspection department to move on from the idea of controlling the taxpayer to the idea of helping them to establish better accounting system to avoid the potential risk of tax penalty by offering guidance of tax risk management. As a result, contradiction of the taxpayer and the collector can be avoided, which leads to a real win-win situation.

\section{Existing Problems}

At the back ground of modern information technology, there are several problems in tax inspection considering the methods and ability of processing information.

(1) Extremely Limited Inspection Area.

Considering the vast number of taxpayers, tax inspectors are far form enough to guarantee all-round inspection. The inspection task is so heavy that inspection department has to adopt a spot check policy. Despite the high amount of per capita inspecting and paying overdue tax, coverage of tax inspection is narrow and inspection ability is relatively inadequate.

(2) Compromising Efficiency and Quality of Tax Inspection.

At present, tax inspection is mainly based on manual work although electronic audition software is partly used in selecting, adding up and verification, which means doubtful cases can only be inspected and analyzed manually. To make up for the outdated inspection method, a lot of human resource has to be devoted to tax inspection but even in this way the efficiency and quality of tax inspection can hardly be guaranteed. Relied on personal knowledge level and individual preference, the inspection work is not able to identify problems fully or thoroughly. 
(3) Difficulty to Promote Electronic Audition.

In recent years, electronic audit began to be carried out the in tax inspection area and there are many problems need urgent solution. If one of the tax inspection departments decided to carry out electronic audition, the vast cost on purchasing specialized software and hardware along with maintainers would be incredible. What's worse, there are varieties of auditing software and all of them have flaws.

(4) Limited Inspection Scope.

Tax inspection generally focus on the tax collecting and administration information such as tax declaration and accounting charts. Furthermore, sometimes it is necessary to analyze information of third party, to consult taxpayers and observe the how they product or operate in order to make fare judgments. However, only a few of these respects can be inspected in actual work due to the shortage of inspector and lack of ability.

\section{Continuous Tax Inspection}

Continuous Tax Inspection is a new inspection mode equipped with information technology which is able to carry out automatic inspection as soon as taxpayers complete the business and this process is continuous.

Using the idea of Continuous Auditing, Continuous Tax Inspection means real-time check .Continuous audit refers to a kind of audit type that can produce the result of audit in the same time, or after a short period of time when related events happen. It is a kind of real-time audit. Although the idea of continuous audit has been put forward for a long time, it is in last several years that the idea has been put into practice. The development of information technology makes it possible. On one hand, data can be attained on time with the help of advanced network technology. On the other hand, artificial intelligence techniques and other related technologies makes it possible to achieve intelligent data processing and automatic auditing. Setting aside the difference of purpose, scope, subject, foundation and method between tax inspection and tax audition, the nature of them is inspection and it is also possible for tax inspection to take advantage of information technologies to achieve continuous tax inspection.

Implementation of continuous tax inspection needs the support of advanced information technologies to make sure that information can be intelligently obtained and processed on time.

Compared with traditional tax inspection mode, continuous tax inspection has following characteristics.

(1)Timeliness. With the help of information-based method, digital evidence can be delivered to tax inspection department in time so that it can be processed without delay, which means shorter inspection cycle.

(2)Continuity. Continuous tax inspection goes with the process of business automatically rather than raids on taxpayers or stage inspection.

(3)Comprehensiveness of inspection. Apart from tax collecting and administration information such as tax declaration and accounting charts, business information of taxpayers are also accessible. Moreover, these information can be processed and checked automatically by system, which indicates the transformation of tax inspection from limited manual work to overall automatic work.

(4)Information processing automation and intelligence. Adopting artificial intelligence technology, the information system can process collected digital evidence automatically and intelligently. As a result, tax inspection can be much more efficient. 


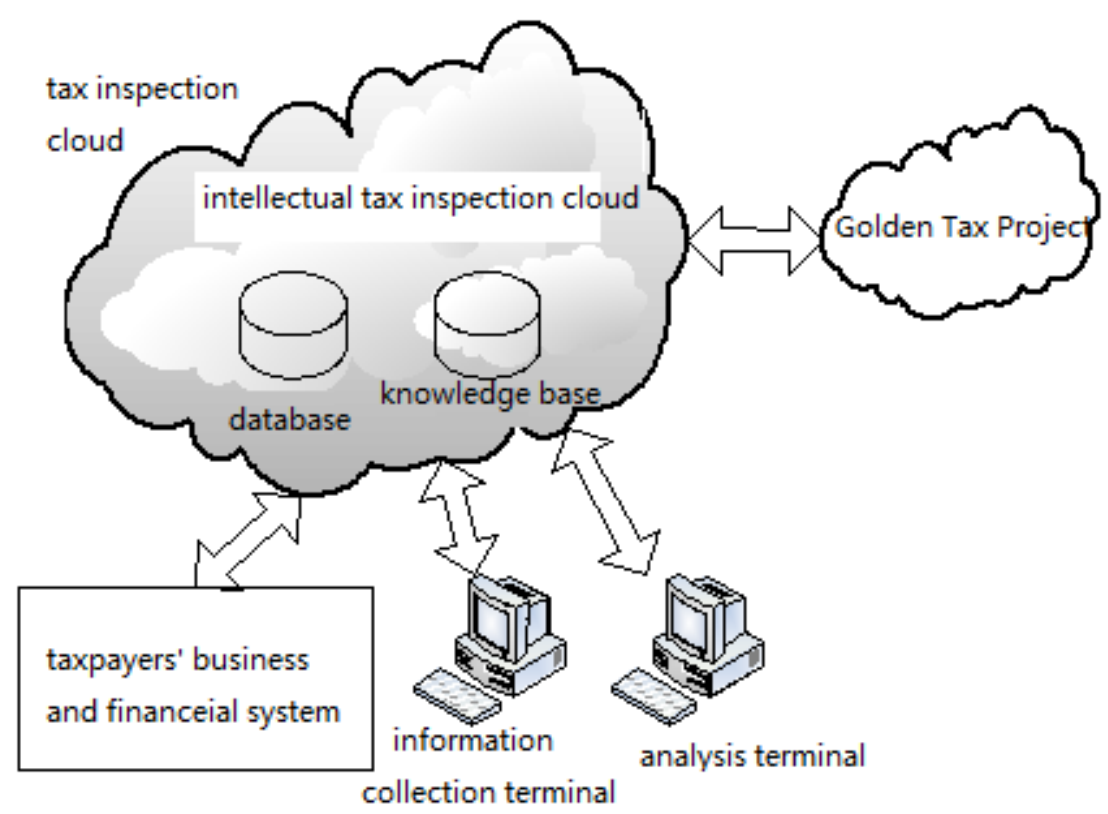

Fig. 1 Logic Model of Continuous Tax Inspection

Continuous tax inspection is a brand new inspection model whose implementation needs the support of advanced information technology to achieve the goal of long-distance and real-time inspection. The logic model of continuous tax inspection is illustrated above. Cloud computing platform is used to realize back end system of tax inspection and finally establish tax inspection cloud. Tax inspection cloud is composed of server hardware, system software, database, knowledge base, and intelligent tax inspection software. Tax-related information of taxpayers can be automatically referred to tax inspection cloud through interface software and eventually stored in database. Besides, tax officials can submit manually obtained digital evidence to the cloud through evidence collection terminal. The interface between tax inspection cloud and Golden Tax system is designed for extracting tax-related information. Knowledge like inspection rules, data mining method library and semantic library are stored in knowledge base that provides knowledge support for intelligent data processing. Intelligent tax inspection software automatically processes the data in database base on the knowledge extracted from knowledge base. Analysis terminal provides an interface to tax officials.

There two basic work patterns based on this model. The first pattern is designed for taxpayers equipped with accounting software and tax-related data can be uploaded automatically to tax inspection cloud through interface program. In this way, tax inspection cloud can provide taxpayers with guidance on tax risk management at the same time as tax department identifying questionable points online. Another pattern is meant for tax inspectors submitting manually obtained digital evidence to tax inspection cloud through collecting terminal. It allows system to analyze the data automatically as well as manually analysis.

Using the most advanced information technology, continuous tax inspection model has more advantage over traditional electronic auditing. For taxpayers equipped with accounting software and tax-related data, their tax-related information can be uploaded automatically to tax inspection cloud through interface program, thus achieve the goal of real-time, continuous inspection.

(1)Lower informatization cost of grass-root taxation departments

With server hardware and software deployed in the cloud, grass-root taxation departments are free from extra investment. They can use browser installed on normal personal computers to work as long as they have access to Government Intranet. As a result, there is no need to assign any person to manage or maintain the system. Compared with traditional inspection pattern, the manpower, material and financial cost of the informatization of the tax inspection are relatively lower.

(2)Higher level of knowledge sharing

Tax inspection knowledge base is stored in the cloud. Common sense knowledge, expert knowledge and tax officials' experience is transformed into inference rules, ontology, data mining 
model and analysis model. Stored in the cloud, the knowledge base is shared by grass-root departments. If new doubt identification model is concluded during operation, system administrator would update knowledge base so that all access department can share this new model.

(3) Slighter influence on taxpayers' business

After the interface program installed on front end of financial software and business software, all of the functions are completed automatically without having any influence on taxpayers' business.

\section{Technical analysis}

Smooth operation of continuous tax inspection model is based on related techniques.

\subsection{Cloud Computing.}

Cloud computing is a new computing model springing up in recent years whose software and hardware are deployed in the cloud. Consumers pay for the service but they do not own it. Using the Golden Tax Project for reference, continuous tax inspection system focus on taxation bureau of each province and establish provincial tax inspection cloud with the help of cloud computing technology. All of the server hardware and software are deployed in provincial center of data processing thus the center is responsible for system maintenance and data maintenance. Tax officials at all levels have easy access to the system as long as they are equipped with a net-connected computer. They can use the system via web browser so that they are free from the trouble of installing applications. Grass-root taxation departments don't have to invest equipment or specialized person in maintenance of tax inspection system which means low threshold of informatization.

Tax inspection cloud can be connected to Golden Tax system so that it can fetch tax-related information automatically and enhance comparison.

\subsection{Data Fusion Technology.}

Whether automatically obtained digital evidence or manually extracted digital data faces the heterogeneity of data. Exported from different enterprise, institution and accounting system, both format and content of data could be different. For financial data, this is not a serious problem thanks to state standard GB/T24589-2010 that is also known as Data Interface for Financial Accounting Software Information Technology. All the accounting software sold in the market is supposed pass the compliance tests described in the standard so that data exported from them is standardized. With processing ability improving, those business data that inspectors were unable to take into account now can be automatically fetched and processed by software. Besides, data heterogeneity caused by the difference between business systems can be solved by data fusion technologies such as XBRL (Extensible Business Reporting Language) and ontology.

XBRL is a type of mark language developed based on XML (Extended Mark Language) and it is widely used in business and financial information interchange and definition. International Union of XBRL is responsible for the establishment and management of the standard. The institution consists more than 300 members such as Morgan Stanley, PwC, Microsoft and Deutsche Bank. Using XBRL, we can unify the information definition and interchange standard among different systems and achieve data fusion between systems. It is especially suitable for the fusion of accounting data and business data.

The basic approach of ontology is to establish domain knowledge base first and then make the data understandable for machine with the help of semantic annotation so that reference engine can process it. Data stored in computer system is understandable to human instead of machine. With the help of ontology, computer system is able to understand the meaning of data thus process the data automatically and intelligently.

\subsection{Technology of Systems Interoperability.}

Interoperability refers to the ability to exchange and use information in a large heterogeneous network made up of several local area networks and one system's ability to receive and process information sent by another system. In continuous tax inspection model, tax inspection cloud needs taxpayers and business software to interoperate and extract tax-related information and business information automatically. However, variety of financial software and difference of technical 
background make it even harder to interoperate with tax inspection cloud. SOA (Service Oriented Architecture) can preferably solve these problems.

SOA is a type of software architecture that abstract different functional units into service and bond them by well-defined interfaces and agreements. These interfaces and agreements are independent from hardware environment, operating system and programming language and each service interact in a unified and universal way. In continuous tax inspection model, this technology is able to tackle heterogeneous financial and business software and enable the software to upload data to tax inspection cloud automatically.

\subsection{Intelligent Processing Technique.}

There are a huge number of automatically extracted or manually obtained digital data and evidence, a complex articulation, covert acts of tax evasion. It can make use of intelligent processing technologies automatic processing, increase processing capacity, efficiency and accuracy.

Artificial Intelligence is the study of how to make the computer do intelligent work which only people can do before. In continuous tax inspection model, contents like the common sense type of knowledge, expert knowledge and the experience of tax officials can be organized into the knowledge base which computer systems can reasoning, such as rule-based knowledge base, to achieve intelligent analysis of the data, identify exceptions and problems. The ontology is also a branch of artificial intelligence technology which makes the data in the form of the semantics of the presence of well-formed, the computer can understand their meaning, intelligent processing of data can be achieved.

Data mining integrated applies statistical methods, artificial intelligence technology to analysis data and to look for patterns. Types of data mining includes association analysis, cluster analysis, classification analysis, anomaly analysis, analysis of specific groups and evolution analysis. We can quickly find anomalies in massive data by using data mining on taxpayers' tax-related data.

Behavior pattern recognition is one of data mining methods. First, it is based on a large number of specific behavior analysis, statistics and computing, to establish some patterns of behavior data model, then it uses this model to analyze the data and finds activities fitting with the behavior patterns. Although people who want to tax evasion rack their brain, but some behavioral chain method has certain characteristics which can be used to establish behavior pattern recognition model for tax evasion, and it is possible to find out the inter association from large number of discrete data, and then suspicious behavior.

\section{Challenges}

Continuous tax inspection is facing some challenges in the process of implementation.

Artificial intelligence can take the place of human to finish a part of work but it is not omnipotent. In continuous tax inspection, computer system is able to identify some problems rather than all the problems. The quality of artificial intelligence largely depends on the quality of knowledge base and the accuracy of model. It is a great challenge for knowledge engineers to sort out knowledge from common sense knowledge, expert knowledge and experience of tax officials and to establish accurate analysis and recognition model.

Data fusion technology is able to solve data heterogeneity and enable tax inspection cloud understand data obtained from different sources. Interoperability technology make it possible for tax inspection cloud to obtain information through interacting with financial system and business system. Under extreme circumstances of interoperability, each financial system and business system must be implemented with specialized plan and workload of development can be challenging.

Financial system state is under the constraint of standard GB/T24589-2010 that is also known as Data Interface for Financial Accounting Software Information Technology while business system is not. It is also a challenge to get data from different business system and make sense of it. Continuous tax inspection model is meat for digital data that is traceless, mutable and duplicatable. Digital data can be used as digital evidence. Taking subjective and objective factors into account, data authenticity may be compromised in the process of validation and preservation. As is ruled in Notice 
of the State Administration of Taxation on the Implementation of the Law of the People's Republic of China on the Administration of Tax Collection and Its Implementation, tax authorities are authorized to enter taxpayers' computerized accounting system and copy tax-related digital data as evidence. On the other hand, tax authorities are responsible for the burden of proof and the authenticity and validity of data.

As is mentioned in the 54th, 56th, 58th item of Tax Administration Law, tax inspectors are authorized to check the information of taxpayers' accounts. Under the circumstances where taxpayers wouldn't cooperate, tax authorities can obtain the data according to prescribed procedure and methods as long as data is locally stored. However, tax authorities would face the challenge that data cannot be obtained if taxpayers use the latest cloud computing technology, software-as-a-service. Financial software adopting software-as-a-service model stores the data in the cloud and financial data cannot be obtained locally. Tax payers only pay for the services and use the software via Internet browsers. What's more, the cloud server might be deployed abroad thus bring out jurisdiction issue.

Continuous tax inspection demands that taxpayers should upload financial data and business data to the tax inspection cloud in real time. Taxation is a process of wealth transferring and it cannot be accomplished unless taxpayers understand and cooperate. Many taxpayers consider tax inspection as problem searching and penalty instead of its service functions. Helping taxpayers to improve their accounting system and to avoid potential risk of penalty is one of these functions. It is also a challenge to taxpayers' view.

\section{Strategies}

Challenges facing continuous tax inspection cannot be solved in a short term. However, we can focus on these challenges and further sort out the approaches and strategies.

To create a high-quality knowledge base required the participation of computer professionals, tax collector and tax inspectors. They complement each other in personnel knowledge structure in order to complete a good knowledge induction and consolidation work. Moreover, this work is not a one-time work, with the new trends and new features of tax inspection practice found, it needs induction and summary in time, also updates of the knowledge base.

Excellent software architecture design, can more easily achieve interoperability of heterogeneous information systems. Tax inspection cloud using SOA technology, through a loosely coupled manner, standardized interfaces, compresses the differences of system interfaces to a local point, then resolves them one by one, which can achieve financial software and business software and tax inspection cloud interoperability.

"Software as a service" issues are new. The problem of the isolation of software, data and the taxpayer in space can be resolved by constraining the service providers. Registration can be used the way, requiring service providers to put on records for each customer in the relevant government departments which can be used to look for tax-related evidence by tax inspection departments.

Continuous tax inspection can be carried out int some large enterprises. Major taxes risk they face is not subjective intention to tax evasion, but that there is a deviation understanding of tax policy. They need tax inspection services to help them self-examination, identify potential problems and reduce risk. And large enterprises has a high degree of informatization, data fusion and interoperation is relatively easy to achieve.

\section{Summary}

Continuous tax inspection is not a purely technical issue, it also brings tax inspection pattern changes which help to improve the quality and efficiency of tax enforcement, contribute to the tax inspection department to carry out public social services. Although there are many specific challenges in implementation, we can solve the problem step by step after determining the overall solutions, and eventually build a good environment for continuous tax inspection. 


\section{References}

[1]. China Taxation. A Closer Look at Golden Tax Project: Paper Collection of Taxation informatization[C]. China tax Publishing House, 2011.

[2]. Jing Bo. Research on Continuous Tax Inspection Model Based on Electronic Forensics. Journal of Nanjing Audit University, 2011.

[3]. Zhao Xianming. Game Analysis of Financial Information Standard Based on XBRL. Chinese Journal of Management.

[4]. The State Council Legislative Affairs Office. China Tax Collection and Management Measures[S]. China Legal Publishing House, 2010.

[5]. Liu Peng. Cloud Computing [M]. Publishing House of Electronics Industry, 2010

[6]. Wang Liming, Wang Xiaowen. Thoughts on Present Situation of Tax Inspection Under the Circumstances of Accounting Computerization [J]. Research of Finance and Accounting, 2013.

[7]. Chen Ping, Zhang Li. Application of Cloud Accounting in Taxation in Era of Big Data [J]. Friends of Accounting, 2015.

[8]. Sun Yi. Challenges and Strategies Concerning Taxation In Era of Big Data [J]. Academic Exchange, 2015.

[9]. Qiao Xiaofeng Application of Cloud Computing in Tax System: Taking Beijing Tax Bureau for Instance [J]. China Taxation, 2014.

[10]. Tang Ning. The Prospect of Municipal Tax System Based on Cloud Computing Platform [J]. China Computer \& Communication, 2014.

[11]. Sun Yicheng. Opportunity \& Challenges Facing Cloud Computing in Taxation Informatization Construction [J]. Electronics world, 2013.

[12]. Liu Dan, Hu Ying. Tax Inspection Experience in New Environment of Computerized Accounting [J]. Friends of Accounting, 2012.

[13]. Zhang Jianguang, Zhu Jianming, Zhang Xiang. Discussion on Construction Mode of Taxation Informatization Based on Cloud Computing [J]. Taxation Research, 2013.

[14]. Li Jiujin, Xu Chang. Method to Improve Tax Inspection in the Environment of Accounting Informatization [J]. Finance and Accounting Monthly, 2007. 